Vol 12, Issue 4, 2019

\title{
EFFECTS OF PHENOLIC COMPOUNDS EXTRACTED FROM SALVIA FRIGIDA ON INDUCED HYPERURICEMIA IN MICE
}

\author{
MUHAMMAD ABDULHUSSEIN AL-DABBAGH ${ }^{1 *}$, SHIHAB ABDULRAHMAN SHIHAB ${ }^{1}$, ENAS JAWAD KADHIM ${ }^{2}$
}

${ }^{1}$ Department of Pharmacology, College of Medicine, Al-Nahrain University, Baghdad, Iraq. ${ }^{2}$ Department of Pharmacognosy, College of Pharmacy, University of Baghdad, Baghdad, Iraq. Email: mhmd_aldabbagh@yahoo.com

Received: 19 February 2019, Revised and Accepted: 09 March 2019

\begin{abstract}
Objective: The aim of this study was to investigate effects of phenolic compounds rich fraction extracted from aerial parts of Salvia frigida on serum uric acid (SUA) and xanthine oxidase (XOD) in hyperuricemic mice model.

Methods: A total of 40 albino male mice were equally divided into four groups. The blank group was given vehicles only. The model of hyperuricemia was induced by single intraperitoneal injection of UA $(250 \mathrm{mg} / \mathrm{kg})$. S. frigida group was pretreated orally with phenolic compounds rich fraction $\left(300 \mathrm{mg} / \mathrm{kg}\right.$ ) for 6 days and one final oral dose was given directly after the UA injection on the $7^{\text {th }}$ day as an acute treatment and the same was applied to allopurinol $(20 \mathrm{mg} / \mathrm{kg})$ which served as a positive control. $1 \mathrm{~h}$ later blood was withdrawn to be tested for SUA, XOD, and creatinine levels. Furthermore, the body weights were daily documented before each administration.
\end{abstract}

Results: The results revealed a highly comparable significant reduction in SUA and XOD in both S. frigida and allopurinol groups without significantly affecting serum creatinine compared to model group, also both modestly decreased the body weights of mice.

Conclusion: S. frigida significantly reduces SUA in the hyperuricemic model and may also have a promising effect on weight management.

Keywords: Uric Acid, Xanthine Oxidase, Urate Lowering Therapy, Flavonoids, Quercetin, Allopurinol.

(C) 2019 The Authors. Published by Innovare Academic Sciences Pvt Ltd. This is an open access article under the CC BY license (http://creativecommons. org/licenses/by/4. 0/) DOI: http://dx.doi.org/10.22159/ajpcr.2019.v12i4.32096

\section{INTRODUCTION}

Hyperuricemia defined as the presence of elevated serum UA (SUA) concentration. UA is the end product of purine metabolism in human [1]. El-Yassin et al. (2012) found that $19 \%$ of a sample of Iraqi subjects from Karbalaa city has elevated levels of SUA [2]. Hyperuricemia complications can lead to gout and nephrolithiasis and increase the risk of cardiovascular diseases, metabolic disorders, and chronic kidney disease [3-9].

There are currently few approved urate-lowering therapies (ULTs) available in clinical practice at the same time they have several drug interactions, contraindications, side effects, and sometimes unfortunate severe adverse effects. The global rising burden of hyperuricemia together with the increased evidence that linked hyperuricemia to the pathogenesis of other diseases and the lack of the perfect agent to treat it further emphases the importance of the urgent need for developing new ULTs.

Natural plant-derived phenolic compounds, especially flavonoids have showed potential SUA lowering effect by xanthine oxidase (XOD) inhibitory action $[10,11]$ and/or uricosuric effect $[10,12]$ in addition to antioxidant and anti-inflammatory effects [10]. The dual effect as a XOD inhibitor (XOI) and a free radical scavenger, suggests new promising therapeutic perspective to prevent hyperuricemia and its complications, as UA can induce oxidative stress, inflammation, and tissue injury [10].

Salvia frigida Boiss. (Family: Lamiaceae) exhibited in vitro inhibition to XOD [13]. To the best of our knowledge, no in vivo study is available to assess its effects on model of hyperuricemia. Accordingly, this study has explored S. frigida Boiss. aerial parts ethanolic extract; phenolic compounds rich fraction, for potential promising urate lowering effect in hyperuricemic mice model.

\section{MATERIALS AND METHODS}

\section{Materials}

Allopurinol tablets (Aspen, Germany), carboxymethyl cellulose sodium salt (CMC-Na) (Panreac, Spain), methanol high-performance liquid chromatography (HPLC) grade $99.9 \%$ (GCC, UK), myricetin, quercetin, and rutin standards (Chengdu Biopurify, China), UA powder (Downs development, England), and XOD ELISA kit for mice (Al-Shkairate establishments, Jordan) were used. All other chemicals are of the highest purity obtained from reputed sources. Animal feeding needle curved $20 \mathrm{G} \times 1^{\prime \prime}$ (2 mm tip diameter) Reusable (Petsurgical, India), Cobas c 111 analyzer (Roche, Switzerland), high performance liquid chromatography (HPLC) (Waters, Germany), Rotatory evaporator (Buchi, Switzerland), Soxhlet (Labtech, Korea).

\section{Plants}

Salvia frigida Boiss. was provided by the Herbarium of Department of Biology, College of Science, University of Baghdad.

\section{Animals}

A total of 40 apparently healthy albino male mice weighing between 25 and $30 \mathrm{~g}$ were included in the study and were randomly divided into four groups (10 mice each). The mice were obtained from the National Center for Drug Control and Research/Ministry of Health/Baghdad. Each group was kept in a separated plastic cage, had free access to water and pellet diet, maintained at $12 \mathrm{~h}$ light/dark cycles with room temperature $\left(22-25^{\circ} \mathrm{C}\right)$, and habituated for a week before starting with the in vivo study.

\section{Approval of methods}

The study protocol was approved by the Institutional Review Board at College of Medicine, Al-Nahrain University. Plant extraction and HPLC analysis were conducted at Pharmacognosy Department, College of Pharmacy, University of Baghdad. 
The in vivo study was conducted at the laboratories of the Pharmacology Department/College of Medicine/Al-Nahrain University. The study was started during May 2018 and the thesis was completed in December 2018 .

\section{Extraction of plants}

Dry powdered aerial parts plant (250 g) was defatted with hexane for $24 \mathrm{~h}$ then allowed to dry at room temperature. The defatted plant materials were extracted with $80 \%$ ethanol (1 l) in Soxhlet apparatus until complete exhaustion.

The alcoholic extract was evaporated under reduced pressure at a temperature not exceeding $40^{\circ} \mathrm{C}$ to give a residue designated as a crude fraction.

Crude fraction was acidified with hydrochloric acid (5\%) to pH 2 and partitioned (three times) with an equal volume of ethyl acetate to get two layers (aqueous acidic layer and ethyl acetate layer)

The ethyl acetate layer designated as fraction 1 was separated and evaporated to dryness under reduced pressure and basified with $300 \mathrm{ml}$ of sodium hydroxide $5 \%$ to $\mathrm{pH} 10$ and extracted with chloroform in the separatory funnel to get two layers, the aqueous basic layer and chloroform layer.

The aqueous basic layer designated as fraction 2 was separated, evaporated to dryness and acidified with $5 \%$ hydrochloric acid to $\mathrm{pH} 2$ then extracted with ethyl acetate to get the final fraction designated as fraction 3 (F-3) which after being subjected to evaporation process represents the phenolic compounds rich fraction that was used for formulating oral formula for in vivo administration. The previously mentioned procedure is according to Kadhim (2013) [14].

\section{Preliminary qualitative phytochemical analysis}

\section{Test for flavonoids}

a. $\mathrm{NaOH}$ test: To $5 \mathrm{ml}$ from the crude extract was treated with aqueous $\mathrm{NaOH}$ and $\mathrm{HCl}$, looking for the formation of yellow-orange color [15].

b. Lead acetate test: To a $5 \mathrm{ml}$ of F-3 fraction, $1 \mathrm{ml}$ of $10 \%$ lead acetate solution was added. The formation of a yellowish-white precipitate indicates a positive for flavonoids [15].

\section{Test for phenolic compounds}

Ferric chloride test: A little of F-3 fraction was dissolved in distilled water, $2 \mathrm{ml}$ of $5 \%$ ferric chloride solution was added to it. Formation of violet, blue or green color indicates the presence of phenolic compounds [16].

\section{Flavonoids identification using HPLC technique}

The identification of flavonoids was done with HPLC. The identifications were made by comparing the retention times obtained at identical chromatographic conditions between extract fraction and standards. $1 \mathrm{mg}$ from the extracted fraction was dissolved in $1 \mathrm{ml}$ ethyl acetate, and $20 \mu \mathrm{l}$ from this solution was injected into the HPLC. The standards were prepared as solutions with a concentration of $1 \mathrm{mg} / \mathrm{ml}$ for each. The solvent used for dissolving the standards was methanol. $20 \mu \mathrm{l}$ from each solution was injected into the HPLC for each run in HPLC.

The experimental conditions of HPLC were:

- Mobile phase: Mixture of methanol:water (70:30) [17]

- Column temperature $25^{\circ} \mathrm{C}$

- Column ODS C18 (250 mm×4.6 mm, $5 \mu \mathrm{m}$ particle size)

- Flow rate $1 \mathrm{ml} / \mathrm{min}$

- Detection wavelength $265 \mathrm{~nm}$ [18]

\section{Experimental design}

The induction of hyperuricemia model was done by a single intraperitoneal (i.p.) injection of UA, at a dose of $250 \mathrm{mg} / \mathrm{kg}$ [19] in $0.5 \% \mathrm{w} / \mathrm{v} \mathrm{CMC}-\mathrm{Na} /$ normal saline, to be given on the $7^{\text {th }}$ day of the study right before the oral administration of either tested $S$. frigida F-3 fraction, vehicles, or allopurinol.
The study groups were:

- Group 1: Normal control group (blank group) was given vehicle " $0.5 \%$ CMC-Na/Distal water" $0.2 \mathrm{ml} / 20 \mathrm{~g} /$ day orally for 7 days + single i.p. injection of vehicle " $0.5 \% \mathrm{CMC}-\mathrm{Na} /$ normal saline" $0.2 \mathrm{ml} / 20 \mathrm{~g}$ on the $7^{\text {th }}$ day of the study.

- Group 2: Induced non-treated control group (model group) was given vehicle " $0.5 \% \mathrm{CMC}-\mathrm{Na} / \mathrm{Distal}$ water" $0.2 \mathrm{ml} / 20 \mathrm{~g} /$ day orally for 7 days + single i.p. injection of UA $250 \mathrm{mg} / \mathrm{kg}$ on the $7^{\text {th }}$ day of the study.

- Group 3: The positive control group (allopurinol group) was given allopurinol $20 \mathrm{mg} / \mathrm{kg}$ /day orally for 7 days + single i.p. injection of UA $250 \mathrm{mg} / \mathrm{kg}$ on the $7^{\text {th }}$ day of the study.

- Group 4: $S$. frigida treatment group ( $S$. frigida group) was given phenolic compounds rich fraction "F-3" of $S$. frigida extract $300 \mathrm{mg} / \mathrm{kg} /$ day orally for 7 days + single i.p. injection of UA $250 \mathrm{mg} / \mathrm{kg}$ on the $7^{\text {th }}$ day of the study.

The oral vehicles, $S$. frigida extract, and allopurinol were given daily, every $24 \mathrm{~h}$ for 7 consecutive days. The preparation of CMC-Na $0.5 \% \mathrm{w} / \mathrm{v}$ colloidal solution was based on Kamal et al. (2017) [20] and the United States Pharmacopeia weight variation test was done on allopurinol tablets to ensure proper allopurinol weighing. All the medications were freshly prepared and were given according to the animal body weight which was measured directly before each administration.

\section{Blood collection}

On the $7^{\text {th }}$ day, $1 \mathrm{~h}$ after the last administration, blood samples were collected by cardiac puncture under anesthesia using chloroform. Blood samples were allowed to clot for $1 \mathrm{~h}$ at room temperature, then were centrifuged to obtain serum for measuring UA and creatinine by cobas c 111 analyzer; furthermore, $150 \mu \mathrm{l}$ of serum were stored at $-80^{\circ} \mathrm{C}$ (until testing it later on for XOD by following the kit instructions).

\section{Statistical analysis}

The statistical analysis of this study was performed with the statistical package for the social sciences (SPSS) version 23.0 and Microsoft Excel 2016. Numerical data were expressed as mean \pm standard deviation (SD) and were analyzed using independent Student's t-test (unpaired t-test) for comparison between two groups. Pearson correlation was done between SUA and XOD and expressed as r (correlation coefficient) and its $\mathrm{p}$ value. Paired t-test was used to compare body weight at day 7 (d7) and day 1 (d1) within each study group. For all of the previously mentioned statistical tests, it was considered significant if $\mathrm{p}<0.05$ and highly significant if $\mathrm{p}<0.001$.

\section{RESULTS}

The mean \pm SD for SUA, creatinine, XOD, and the difference in body weight between $\mathrm{d} 7$ and $\mathrm{d} 1$ were measured for the blank group, model group, allopurinol group, and $S$. frigida group.

Analysis of unpaired t-test revealed a highly significant increase $(p<0.001)$ in the level of UA in model group in comparison with the blank group. Furthermore, a statistically significant increases $(p<0.05)$ in XOD in model group compared to blank group. While no statistically significant difference regarding other parameters; almost no change in creatinine levels and very close weight gain occurred in both groups (Table 1).

The results showed a highly significant reduction $(\mathrm{p}<0.001)$ in UA level in both allopurinol group and $S$. frigida group compared to the model group. On the other hand, no significant change in creatinine levels for both groups in comparison with the model group. Serum XOD appeared to be statistically significant $(\mathrm{p}<0.05)$ lower in $S$. frigida group and highly significant $(\mathrm{p}<0.001)$ lower in the allopurinol group compared to the model group. There were statistically significant $(\mathrm{p}<0.05)$ decrease in body weight in both $S$. frigida and allopurinol groups compared to the model group. Numerical results are reviewed in Table 2. 
Pearson correlation between SUA and XOD revealed that only the allopurinol group appears to have a statistically significant $(\mathrm{p}<0.05)$ positive correlation between SUA and XOD. The resultant correlation coefficients and their significance for each group are shown in Table 3.

The mean \pm SD for body weight at $\mathrm{d} 1$ and $\mathrm{d} 7$ were measured for each study group, illustrated in Fig. 1. Analysis of paired t-test revealed a modest decrease in body weight in both allopurinol and $S$. frigida group while statistically significant $(\mathrm{p}<0.05)$ weight gain in both blank and model group were documented.

\section{Preliminary qualitative phytochemical analysis results}

Phytochemical screening was done using colors and precipitates formation after following standard tests for detecting the phytochemicals of interest: Phenolic compounds and flavonoids. S. frigida achieved positive tests for $\mathrm{NaOH}$ (yellow-orange), lead acetate (yellow precipitate), and ferric chloride (dark green) tests.

\section{HPLC results}

The phenolic compounds of $S$. frigida F-3 fraction were identified by HPLC method by comparing them with standard compounds retention times obtained at identical chromatographic conditions of the analyzed samples and authentic standards. HPLC retention times for matching flavonoids were $2.48,3.11$, and 4.48 for rutin, quercetin, and myricetin standards, respectively. The information obtained from the HPLC method of analysis revealed that $S$. frigida is very rich in quercetin. Other flavonols; rutin and myricetin, were also detected still the highest peak was not identified. The peaks extent of $S$. frigida components is shown in Fig. 2.

\section{DISCUSSION}

Hyperuricemia prevalence has increased dramatically throughout the past century reaching to the current dates. It is now a major concern not only because of risking for gout emergence but also it has been recently linked to developing chronic kidney diseases, cardiovascular diseases, and metabolic disorders. Very few ULTs are available with various contraindications and unfortunate adverse effects. In recent years, natural phenolic compounds; especially flavonoids and phenolic acids have been found to possess a promising inhibitory effect on XOD and can decrease UA level with the favorable safety profile and additional antioxidant effect.

This study revealed for the first time major flavonoids constituents of $S$. frigida. The Preliminary analysis results showed that flavonoids class is the richest component of the phenolic compounds content of

Table 1: Comparison between Blank group (Gp1) and model group (Gp2) in relation to serum uric acid, creatinine, xanthine oxidase, and the difference in body weight by unpaired $t$-test

\begin{tabular}{|c|c|c|c|}
\hline Parameters & $\mathbf{n}=\mathbf{1 0}$ & Blank (Gp1) vehicles only & Model (Gp2) UA $250 \mathrm{mg} / \mathrm{kg}$ \\
\hline \multirow[t]{2}{*}{ Serum uric acid (mg/dl) } & Mean \pm SD & $2.05 \pm 0.21$ & $3.63 \pm 0.23$ \\
\hline & $\mathrm{p}$ & & $<0.001^{* * *}$ \\
\hline \multirow[t]{2}{*}{ Serum creatinine (mg/dl) } & Mean \pm SD & $0.18 \pm 0.04$ & $0.18 \pm 0.06$ \\
\hline & $\mathrm{P}$ & & 1.000 \\
\hline \multirow{2}{*}{ Serum XOD ${ }^{1}(\mathrm{pg} / \mathrm{ml})$} & Mean \pm SD & $490.25 \pm 167.71$ & $615.05 \pm 76.07$ \\
\hline & $\mathrm{P}$ & & $0.046^{*}$ \\
\hline \multirow{2}{*}{ difference in $\mathrm{d} 7$ and $\mathrm{d} 1$ weight ${ }^{2}(\mathrm{~g})$} & Mean \pm SD & $1.41 \pm 0.85$ & $1.12 \pm 0.89$ \\
\hline & $\mathrm{P}$ & & 0.469 \\
\hline
\end{tabular}

The hyperuricemic mice model was induced by a single intraperitoneal injection of UA on the $7^{\text {th }}$ day of the study while injecting vehicle to the Blank group. Both groups were given oral vehicles throughout the 7 days. ${ }^{1}$ Xanthine oxidase, ${ }^{2}$ difference in body weight between $\mathrm{d} 7$ and $\mathrm{d} 1,{ }^{*}$ denotes significant difference at $P<0.05,{ }^{* * *}$ denotes highly significant difference at $P<0.001$. UA: Uric acid, d7: Day seven, d1: Day one, SD: Standard deviation

Table 2: Comparison between model group (Gp2), allopurinol group (Gp3), and Salvia frigida group (Gp4) in relation to serum uric acid, creatinine, xanthine oxidase, and the difference in body weight by unpaired $t$-test

\begin{tabular}{|c|c|c|c|c|}
\hline Parameters & $\mathrm{n}=\mathbf{1 0}$ & Model (Gp2) UA $250 \mathrm{mg} / \mathrm{kg}$ & Allopurinol (Gp3) $20 \mathrm{mg} / \mathrm{kg}+\mathrm{UA}$ & Salvia frigida (Gp4) $300 \mathrm{mg} / \mathrm{kg}+\mathrm{UA}$ \\
\hline $\begin{array}{l}\text { Serum uric acid } \\
(\mathrm{mg} / \mathrm{dl})\end{array}$ & $\begin{array}{l}\text { Mean } \pm \text { SD } \\
\text { P }\end{array}$ & $3.63 \pm 0.23$ & $\begin{array}{l}1.12 \pm 0.21 \\
<0.001^{* * *}\end{array}$ & $\begin{array}{l}1.13 \pm 0.32 \\
<0.001^{* * *}\end{array}$ \\
\hline $\begin{array}{l}\text { Serum creatinine } \\
(\mathrm{mg} / \mathrm{dl})\end{array}$ & $\begin{array}{l}\text { Mean } \pm S D \\
P\end{array}$ & $0.18 \pm 0.06$ & $\begin{array}{l}0.2 \pm 0.05 \\
0.433\end{array}$ & $\begin{array}{l}0.2 \pm 0.05 \\
0.433\end{array}$ \\
\hline $\begin{array}{l}\text { Serum XOD } \\
(\mathrm{pg} / \mathrm{ml})\end{array}$ & $\begin{array}{l}\text { Mean } \pm \text { SD } \\
\text { P }\end{array}$ & $615.05 \pm 76.07$ & $\begin{array}{l}431.1 \pm 62.52 \\
<0.001 * * *\end{array}$ & $\begin{array}{l}473.2 \pm 92.11 \\
0.001^{*}\end{array}$ \\
\hline $\begin{array}{l}\text { Difference in d7 and } \\
\text { d1 } 1 \text { weight }^{2}(\mathrm{~g})^{\prime}\end{array}$ & $\begin{array}{l}\text { Mean } \pm \text { SD } \\
\text { P }\end{array}$ & $1.12 \pm 0.89$ & $\begin{array}{l}-0.75 \pm 1.18 \\
0.001^{*}\end{array}$ & $\begin{array}{l}-0.52 \pm 1.18 \\
0.002^{*}\end{array}$ \\
\hline
\end{tabular}

The hyperuricemic mice model was induced by a single intraperitoneal injection of UA on the $7^{\text {th }}$ day of the study while giving oral vehicle throughout the 7 days. Allopurinol and Salvia frigida (phenolic compounds rich fraction) were given orally for 7 days (+ the UA injection on the $7^{\text {th }}$ day) to Gp3 and Gp4 mice groups, respectively. ${ }^{1}$ Xanthine oxidase, ${ }^{2}$ difference in body weight between $\mathrm{d} 7$ and d1. ${ }^{*}$ Denotes significant difference at $P<0.05$ compared to model group, ${ }^{* * *}$ Denotes highly significant difference at $P<0.001$ compared to model group. UA: Uric acid, d7: Day seven, d1: Day one, SD: Standard deviation

Table 3: Pearson correlation between serum uric acid and serum xanthine oxidase within all study groups

\begin{tabular}{|c|c|c|c|c|}
\hline \multirow[t]{2}{*}{$\mathrm{n}=\mathbf{1 0}$} & \multicolumn{4}{|l|}{ Serum uric acid (mg/dl) } \\
\hline & Blank (Gp1) vehicles only & $\begin{array}{l}\text { Model (Gp2) UA } \\
250 \mathrm{mg} / \mathrm{kg}\end{array}$ & $\begin{array}{l}\text { Allopurinol (Gp3) } \\
20 \mathrm{mg} / \mathrm{kg}+\mathrm{UA}\end{array}$ & $\begin{array}{l}\text { Salvia frigida (Gp4) } \\
300 \mathrm{mg} / \mathrm{kg}+\mathrm{UA}\end{array}$ \\
\hline \multicolumn{5}{|c|}{ Serum XOD ${ }^{1}(\mathrm{pg} / \mathrm{ml})$} \\
\hline$r^{2}$ & -0.089 & -0.081 & 0.688 & 0.597 \\
\hline$P$ & 0.807 & 0.815 & $0.028^{*}$ & 0.069 \\
\hline
\end{tabular}

*Denotes significance at $P<0.05$. The hyperuricemic mice model was induced by a single intraperitoneal injection of UA on the $7^{\text {th }}$ day of the study while giving oral vehicle throughout the 7 days. Blank group mice $(\mathrm{Gp} 1)$ were given vehicles only. Allopurinol and phenolic compounds rich fractions from Salvia frigida were given orally for 7 days (+ the UA injection on the $7^{\text {th }}$ day) to Gp3 and Gp4 mice groups, respectively. ${ }^{1}$ Xanthine oxidase, ${ }^{2}$ correlation coefficient. UA: Uric acid, d7: Day seven, d1: Day one, SD: Standard deviation 
S. frigida. Quercetin is abundant in S. frigida; it appeared as the second highest peak. Still, the highest peak and several other peaks were not identified. Other detected flavonols in high concentrations were rutin and myricetin. The pharmacological activity of $S$. frigida phenolic compounds rich fraction $(300 \mathrm{mg} / \mathrm{kg} /$ day) appears to be due to those three major flavonoids constituents (quercetin, rutin, and myricetin) in addition to the unidentified highest peak.

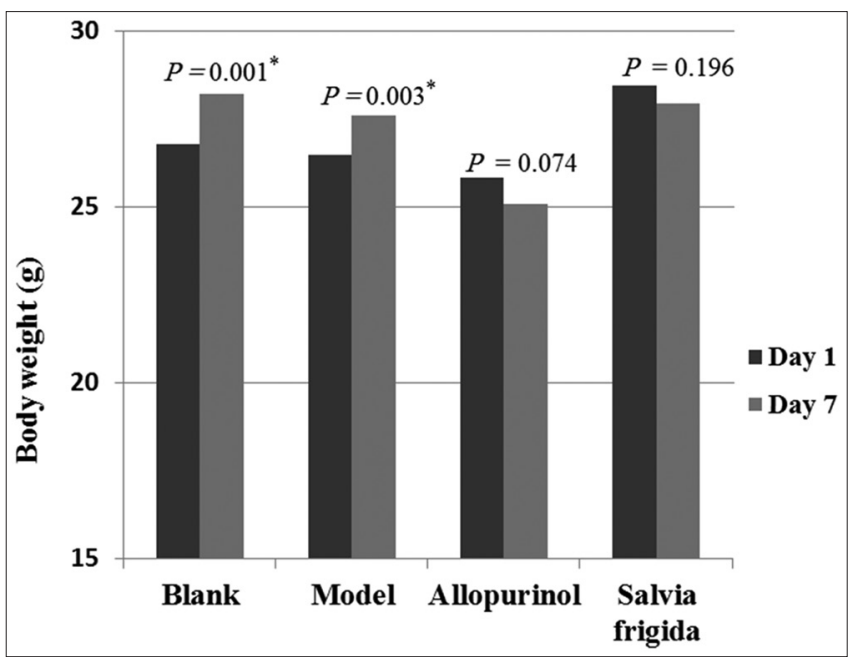

Fig. 1: Comparison between body weight at day 1 (d1) and at d7 within each study group by paired t-test. The hyperuricemic mice model was induced by a single intraperitoneal injection of uric acid (UA) $250 \mathrm{mg} / \mathrm{kg}$ on the $7^{\text {th }}$ day of the study while giving oral vehicle throughout the 7 days. Blank group mice were given vehicles only. Allopurinol $20 \mathrm{mg} / \mathrm{kg}$ and phenolic compounds rich fractions $(300 \mathrm{mg} / \mathrm{kg})$ from $S$. frigida were given orally for 7 days (+ the UA injection on the $7^{\text {th }}$ day) to their corresponding mice groups, respectively. Data represent mean \pm standard deviation for 10 mice. *Denotes significant difference at $p<0.05$ compared with d1
In this study, single i.p. injection of UA $(250 \mathrm{mg} / \mathrm{kg})$ on the $7^{\text {th }}$ day of the study to model group while giving vehicle orally throughout the previous days was resulted in marked hyperuricemia, being measured after $1 \mathrm{~h}$ of the last administration, compared to blank group, with a highly significant increase in SUA levels (Table 1). These findings are in agreement with reported protocol by Chen et al. (2006) who found a significant increase in SUA concentration even after 10 min from injecting the same dose into mice [19].

To the best of our knowledge, the current study is the first to report serum XOD concentration in mice under such conditions. It revealed that circulating XOD has mildly increased to a level that reaches statistical significance. The mildly elevated levels of mean serum XOD enzyme may indicate increased permeability, damage, or necrosis of tissues which is not only a marker of hepatic or intestinal injury but it can also result from a variety of remote organ damage as a consequence of oxidative injury $[21,22]$. This probably occurred in some, but not all ten animals as the results also showed a very week negative correlation (though have not reached statistical significance) between SUA and XOD levels in both blank and model groups (Table 3 ). It has been established that UA acts normally as serum antioxidant [23]; nevertheless, UA may give pro-oxidant activity, mainly intracellularly [24]. It exerts pro-oxidant deleterious effect under several conditions; most importantly when presents at high levels even in the upper two-thirds of physiological ranges [25]. Furthermore, the pro-inflammatory action of UA may induce cell transformation through reactive oxygen species (ROS) and reactive nitrogen species (RNS) generation. Besides, intracellular UA may contribute to decreasing the level of XOD expression [26]. Moreover, UA can actually inhibit XOD and thereby act as a feedback inhibitor of the enzyme; this effect is associated with increased ROS formation [21]. UA may exert a pro-oxidant activity within the cell mainly, possibly due to the free radicals derived from its reaction with ROS, RNS, and nitric oxide (NO), in particular in the presence of myeloperoxidase [24]. Hyperuricemia causes uncoupling of endothelial NO synthase which increases superoxide radical production [25]. UA-derived free radicals have been associated with several effects such as reduced availability of NO, cyclooxygenase-2 expression and up-regulation of the renin/ angiotensin pathway, platelet activation, migration and proliferation of

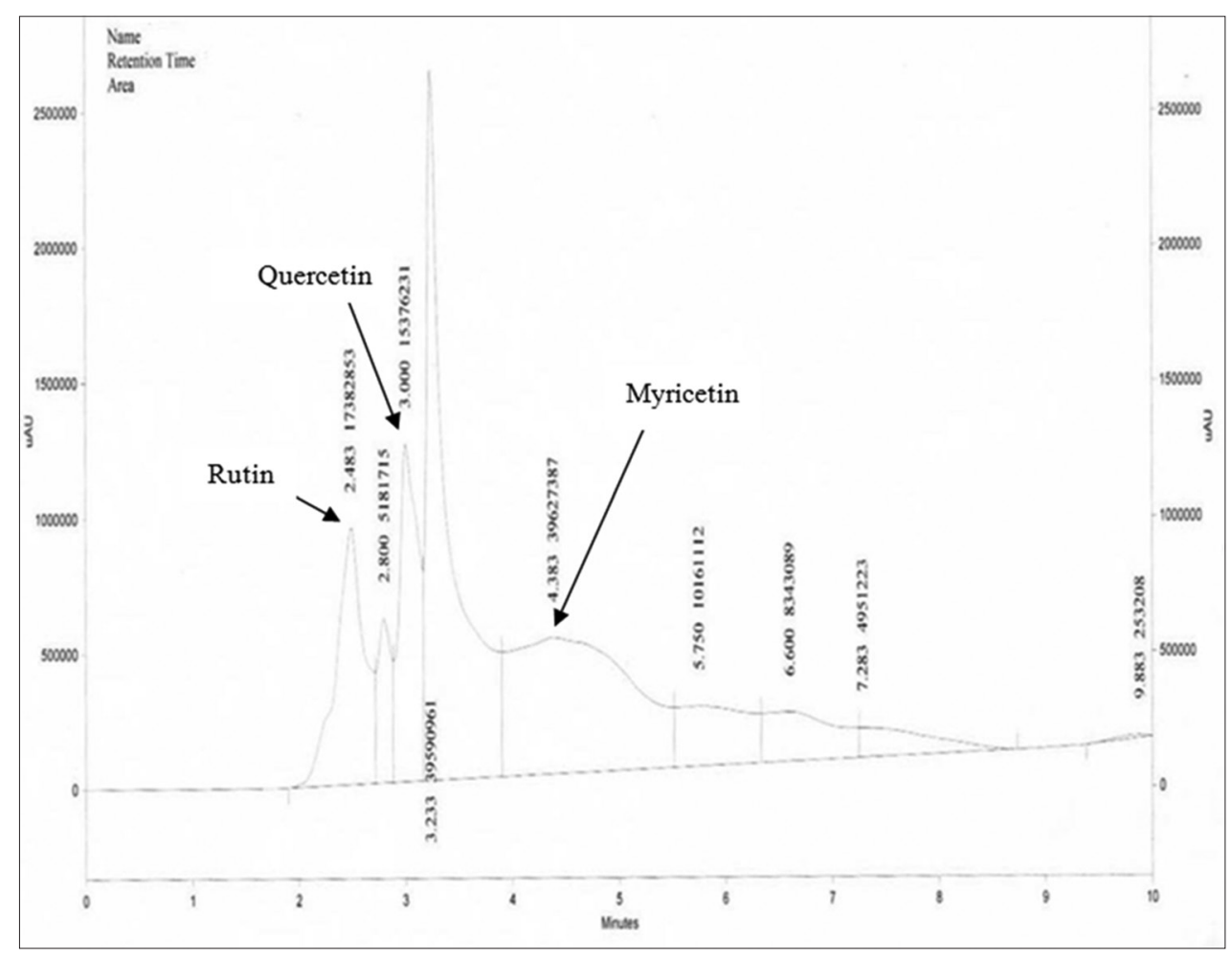

Fig. 2: High-performance liquid chromatography of Salvia frigida 
vascular myocytes, and production of pro-inflammatory cytokines by macrophages [26].

Recently, Wang et al. (2016) have found a significant increase in hepatic XOD activity and protein levels in hyperuricemic mice model [27] while Qin et al. (2018) have found a significant increase in both serum and hepatic XOD activities and hepatic XOD protein levels in hyperuricemic mice model [28]. Serum XOD enzyme activity has significantly increased in several studies using various hyperuricemic models in rodents compared to blank controls $[19,29]$. Increased XOD activity could induce oxidative stress through ROS and UA production. XOD pathway is an important path in the oxidative damage to tissues. The UA conversion from hypoxanthine and xanthine by XOD is accompanied by the generation of superoxide anion and hydrogen peroxide and eventually give rise to hydroxyl radical through the Haber-Weiss and Fenton reactions in the presence of transition metals [4,26,30-32]. These cytotoxic ROS are highly reactive and can directly oxidize macromolecules including DNA, protein, and lipids [30,31] which may result in cellular damage when produced in large amounts [32]. Furthermore, XOD activities may produce RNS, although other enzymes are implicated in the generation of these [26] as with highly reactive peroxynitrite (OONO-) [33,34]. Accordingly, in this study, lipid peroxidation mediated by ROS and RNS has probably caused cell membrane damage leading to the release of XOD into the serum.

Humans have only $1 \%$ activity of XOD compared with other mammals. The decrease in XOD activity is one likely evolutionary adaptation to uricase loss in humans [35] as the sudden knockout of uricase in mice appears to be fatal due to striking increase in SUA levels which cause acute urate nephropathy and renal failure [36]. No significant change in creatinine occurred in model group as the elevation in the serum levels of creatinine can be only noted after extensive kidney injury involving the damage of approximately half of the kidney nephrons [37].

As expected, changes in body weight after 1 week were kind of similar in both model and blank groups. This observation is consistent with Jiang et al. (2017) as they have injected mice intraperitoneally with potassium oxonate $(300 \mathrm{mg} / \mathrm{kg})$ to induce hyperuricemia on the $7^{\text {th }}$ day of the study while giving normal saline to the blank group, noting no significant difference regarding weight gain between the two groups [38]

In the present study, mice were pretreated orally for 6 days with either phenolic compounds rich fraction extracted from S. frigida $(300 \mathrm{mg} / \mathrm{kg})$ or allopurinol $(20 \mathrm{mg} / \mathrm{kg})$ and on the $7^{\text {th }}$ day the mice were given, immediately after the single UA i.p. injection, one final oral dose as an acute treatment. The results revealed excellent hypouricemic effect exerted by $S$. frigida as both $S$. frigida and allopurinol accomplished quite similar highly significant SUA reduction after $1 \mathrm{~h}$ treatment compared to the model group (Table 2). As it has been previously reported that $S$. frigida exert excellent in vitro inhibition to XOD (93.2\%) compared to allopurinol (80.52\%) [13].

The resultant in vivo hypouricemic effect that was achieved by $S$. frigida is probably attributed to XOI effect exhibited by its high flavonoids content. Quercetin probably contributes to the majority of the effect as it represents one of the major constituents of the in vivo tested F-3 fraction and to rutin and myricetin to a lower extent. These conclusions are consistent with several previous studies showing hypouricemic and XOD inhibitory effect exerted by those three flavonols $[39,40]$.

Allopurinol results agree with Qin et al. (2018) as they have shown that allopurinol (20 mg/kg), being orally administered to mice for 7 days, results in significant reduction in SUA level compared to model group with significant inhibition to XOD activity [28].

Another hypothesis behind the hypouricemic effect is proposed by the current study which is a decrease in XOD level equals a decrease in its activity (one enzyme and one reaction) leading to further lowering in
UA production. Both $S$. frigida and allopurinol significantly lowered XOD serum level compared to the model group.

In most biological environments, enzyme concentration is lower than the concentration of its substrate. As long as this is true, there is a directly proportional to relationship between enzyme concentration and its activity. In most situations, decreasing enzyme concentration has a direct influence on its activity since each enzyme molecule is able to catalyze only one reaction at a time. In other words, the rate of the reaction decreases as enzyme concentration decreases [41]. Furthermore, metabolic labeling studies indicate that $\mathrm{H}_{2} \mathrm{O}_{2}$ stimulate the conversion of xanthine dehydrogenase to XOD [42]. Hence, allopurinol's known XOD activity inhibition and $S$. frigida probable XOD activity inhibition have resulted in decreasing $\mathrm{H}_{2} \mathrm{O}_{2}$ production thus decreasing XOD serum presence.

Our hypothesis may also be supported by the correlation results (Table 3) as it obviously showed a positive correlation between UA and XOD expression in both $S$. frigida and allopurinol groups compared to negative ones in both blank and model groups. Although only allopurinol showed statistical significance still, S. frigida showed very close results to reach significance which might only needed a couple of further doses. Still, further investigation is needed for confirming such effects and its extent and for revealing the mechanism behind it.

The current study revealed that $S$. frigida and allopurinol probably prevented organs damage and consequent XOD leak to serum as they both significantly lowered serum XOD level compared to the model group. This may be attributed to $S$. frigida significant antioxidant activity as shown by its remarkable scavenging effect against 2,2-diphenyl1-picrylhydrazyl radical [13]. Likewise, quercetin and rutin have strong antioxidant activities [43]. While the mechanism behind allopurinol protection against UA-induced probable tissue damage is that allopurinol is not only capable of inhibiting XOD activity and reducing UA levels but also it was proven to significantly reduce serum malondialdehyde (MDA) hence further decreases oxidative stress [44].

Analysis of unpaired t-test showed significant growth restraint in both allopurinol and $S$. frigida groups compared to the model group (Table 2). However, the analysis of paired t-test revealed a non-significant decrease in body weight within both allopurinol and $S$. frigida groups (Fig. 1).

Emerging evidence and correlations have linked UA level with body weight. Uricase loss and the consequent increase in SUA level have been hypothesized to give another survival advantage to hominoids. The increased SUA levels may lead to obesity, fatty liver, metabolic syndrome, and diabetes. Hence, uricase knockout subjects could more easily overcome starvation periods [45]. In a clinical study, enrolling patients with cardiac diseases, a positive correlation was detected between the plasma level of XOD activity and B-type natriuretic peptide, as well as with body mass index [46].

In mice, adipose tissue has a very high comparable level of xanthine oxidoreductase (XOR) expression to that of the liver and small intestine. Furthermore, XOR activity is higher in obese mice fat tissue than in healthy controls [47]. Adipogenesis, XOR expression, and amount of UA were increased by subjecting human mesenchymal stem cell-derived adipocytes to fructose. Allopurinol inhibited those effects. Directly treating adipocytes with UA also resulted in enhanced adipogenesis [48]. XOR activity has been portrayed as involved in pre-adipocyte differentiation and adipogenesis in studies carried out in cultured cells and XOD gene knockout mice [49]. Negative effects such as adipogenesis, inflammation, and hypertension are induced by XOR activity on purine metabolism [26]. These results suggest a fundamental role for XOD activity-derived oxidative stress in UAmediated adipogenesis. Interestingly, it has been hypothesized that XOR has a protective role in adipose tissue when the environment allows it to function as nitrate reductase as an adaptive response to obesity- 
consequent hypoxia in fat tissue by activating the reprogramming that leads to browning of the white fat tissue and anti-hypertensive activity [26].

Rutin administration can reduce the mass of adipose tissue and body weight in an obese rat model. Rutin was found to increase mitochondrial DNA content, mitochondrial size, and gene expression related to mitochondrial biogenesis (peroxisome proliferator-activated receptor gamma coactivator- $1 \alpha$, transcription factor A, nuclear respiratory factor-1, and nicotinamide adenine dinucleotide-dependent deacetylase) in skeletal muscle [50].

Allopurinol side effects include nausea, diarrhea, and gastrointestinal intolerance which might also contribute to the weight loss in allopurinol group. Allopurinol results in the present study are in agreement with a previous work that found 7 days allopurinol therapy to significantly inhibit weight growth in hyperuricemic mice model [38].

\section{CONCLUSION}

S. frigida Boiss. and allopurinol have achieved highly similar results with a highly significant reduction in SUA compared to hyperuricemic mice model; making $S$. frigida aerial parts phenolic compounds rich fraction an excellent candidate for further exploration in the goal of developing newer and possibly safer urate-lowering therapy. Furthermore, S. frigida mildly decreased body weight of mice; such modest action suggests a useful application in developing weight control therapy from S. frigida phenolic compounds content.

\section{ACKNOWLEDGMENTS}

This study is abstracted from M.Sc. thesis by Muhammad Al-Dabbagh. He thanks the staff of the Department of Pharmacology, College of Medicine, Al-Nahrain University for their support and the Herbarium of the Department of Biology, College of Science, University of Baghdad for supplying the herb.

\section{AUTHORS' CONTRIBUTIONS}

Muhammad A. Al-Dabbagh has provided the design, intellectual content, innovation, and protocol and has majorly conducted the practical work of the study, interpreted the results and drafted the manuscript. Shihab A. Shihab has helped in drug administration and blood withdrawal along with mentorship. Enas J. Kadhim has suggested the extraction procedure and helped in executing HPLC analysis. All authors have read and approved the final manuscript.

\section{CONFLICTS OF INTEREST}

The author declares that they have no conflicts of interest.

\section{REFERENCES}

1. Song P, Wang H, Xia W, Chang X, Wang M, An L, et al. Prevalence and correlates of hyperuricemia in the middle-aged and older adults in China. Sci Rep 2018;8:4314.

2. El-Yassin HD, Al-Sharifi ZA, Al-Jebuori S. Prevalence of hyperuricemia and its correlation with cardiovascular risk factors in Iraqi subjects of Karbalaa city. J Fac Med Baghdad 2012;54:83-7.

3. Preitner F, Bonny O, Laverrière A, Rotman S, Firsov D, Da Costa A, et al. Glut9 is a major regulator of urate homeostasis and its genetic inactivation induces hyperuricosuria and urate nephropathy. Proc Natl Acad Sci U S A 2009;106:15501-6.

4. Brito R, Castillo G, González J, Valls N, Rodrigo R. Oxidative stress in hypertension: Mechanisms and therapeutic opportunities. Exp Clin Endocrinol Diabetes 2015;123:325-35.

5. Dhandapani C, Shibulal JS, Narayanasamy K. Metabolic evaluation of patients with recurrent and multiple renal stones: A prospective study. Asian J Pharm Clin Res 2016;9 Suppl 3:212-8.

6. Kanbay M, Jensen T, Solak Y, Le M, Roncal-Jimenez C, Rivard C, et al. Uric acid in metabolic syndrome: From an innocent bystander to a central player. Eur J Intern Med 2016;29:3-8.

7. Martinez-Quintana E, Tugores A, Rodriguez-Gonzalez F. Serum uric acid levels and cardiovascular disease: The Gordian knot. J Thorac Dis 2016;8:E1462-6.

8. Tripathi GK, Sharma R, Verma M, Sharma P, Kumar P. Biomarkers in serum, uric acid as a risk factor for Type 2 diabetes associated with hypertension. Asian J Pharm Clin Res 2016;9:352-5.

9. Wannamethee SG, Papacosta O, Lennon L, Whincup PH. Serum uric acid as a potential marker for heart failure risk in men on antihypertensive treatment: The British regional heart study. Int J Cardiol 2018;252:187-92.

10. Gliozzi M, Malara N, Muscoli S, Mollace V. The treatment of hyperuricemia. Int J Cardiol 2016;213:23-7.

11. Boussoualim N, Baghiani A, Krache I, Trabsa H, Kenouf S, Arrar L. Inhibitory effects of Anchusa azurea extracts on xanthine oxidase activity and its hypouricemic effects on mice. Int J Pharm Pharm Sci 2015;7:195-9.

12. Wahyuningsih S, Sukandar EY, Sukrasno, Lofika DN. Antihyperuricemia activity of the ethanol extract of roselle calyx and its fraction (Hibiscus sabdariffa Linn) on male wistar rats. Int J Pharm Pharm Sci 2016;8:278-80.

13. Orhan I, Kartal M, Naz Q, Ejaz A, Yilmaz G, Kan Y, et al. Antioxidant and anticholinesterase evaluation of selected Turkish Salvia species. Food Chem 2007; 103:1247-54.

14. Kadhim EJ. Phytochemical Investigation and Testing the Effect of Iraqi Echinops heterophyllus Family Compositae on Wound Healing [Dissertation]. Baghdad: University of Baghdad; 2013.

15. Khadim EJ, Abdulrasool AA, Awad ZJ. Phytochemical investigation of alkaloids in the Iraqi Echinops heterophyllus (Compositae). Iraqi J Pharm Sci 2014;23:26-34

16. Vimalkumar CS, Hosagaudar VB, Suja SR, Vilash V, Krishnakumar NM, Latha PG. Comparative preliminary phytochemical analysis of ethanolic extracts of leaves of Olea dioica Roxb., Infected with the rust fungus Zaghouania oleae (E.J. Butler) Cummins and non-infected plants. J Pharmacogn Phytochem 2014;3:69-72.

17. Hamad MN. Isolation of rutin from Ruta graveolens (Rutaceae) cultivated in Iraq by precipitation and fractional solubilization. Pharm Glob 2012;3:1-3.

18. Orhan IE, Tosun FA, Kök AF. Quantification of genistein and daidzein in two endemic Genista species and their antioxidant activity. J Serb Chem Soc 2011;76:35-42.

19. Chen GL, Wei W, Xu SY. Effect and mechanism of total saponin of dioscorea on animal experimental hyperuricemia. Am J Chin Med 2006; 34:77-85.

20. Kamal SE, Zulfiah RA, Hasyim MF, Jayanti AD. The antipyretic effects test of ethanol extracts of green chiretta herbs (Andrographis paniculata Nees) on male mice (Musmusculus). Dama Int J Res 2017;2:9-15.

21. Pacher P, Nivorozhkin A, Szabó C. Therapeutic effects of xanthine oxidase inhibitors: Renaissance half a century after the discovery of allopurinol. Pharmacol Rev 2006;58:87-114.

22. Voskou S, Aslan M, Fanis P, Phylactides M, Kleanthous M. Oxidative stress in $\beta$-thalassaemia and sickle cell disease. Redox Biol 2015;6: 226-39.

23. Ames BN, Cathcart R, Schwiers E, Hochstein P. Uric acid provides an antioxidant defense in humans against oxidant-and radical-caused aging and cancer: A hypothesis. Proc Natl Acad Sci U S A 1981;78:6858-62.

24. Neogi T, George J, Rekhraj S, Struthers AD, Choi H, Terkeltaub RA, et al. Are either or both hyperuricemia and xanthine oxidase directly toxic to the vasculature? A critical appraisal. Arthritis Rheum 2012;64: 327-38.

25. Hayden MR, Tyagi SC. Uric acid: A new look at an old risk marker for cardiovascular disease, metabolic syndrome, and Type 2 diabetes mellitus: The urate redox shuttle. Nutr Metab (Lond) 2004;1:10

26. Battelli MG, Bortolotti M, Polito L, Bolognesi A. The role of xanthine oxidoreductase and uric acid in metabolic syndrome. Biochim Biophys Acta Mol Basis Dis 2018;1864:2557-65.

27. Wang R, Ma CH, Zhou F, Kong LD. Siwu decoction attenuates oxonateinduced hyperuricemia and kidney inflammation in mice. Chin J Nat Med 2016;14:499-507.

28. Qin Z, Wang S, Lin Y, Zhao Y, Yang S, Song J, et al. Antihyperuricemic effect of mangiferin aglycon derivative J99745 by inhibiting xanthine oxidase activity and urate transporter 1 expression in mice. Acta Pharm Sin B 2018;8:306-15.

29. Cao T, Li X, Mao T, Liu H, Zhao Q, Ding X, et al. Probiotic therapy alleviates hyperuricemia in C57BL/6 mouse model. Biomed Res 2017; 28:2244-49.

30. Enroth C, Eger BT, Okamoto K, Nishino T, Nishino T, Pai EF, et al. Crystal structures of bovine milk xanthine dehydrogenase and xanthine oxidase: Structure-based mechanism of conversion. Proc Natl Acad Sci 
U S A 2000;97:10723-8.

31. Hayyan M, Hashim MA, AlNashef IM. Super oxide ion: Generation and chemical implications. Chem Rev 2016;116:3029-85.

32. Dawson J, Walters M. Uric acid and xanthine oxidase: Future therapeutic targets in the prevention of cardiovascular disease? $\mathrm{Br} \mathrm{J}$ Clin Pharmacol 2006;62:633-44.

33. Godber BL, Doel JJ, Durgan J, Eisenthal R, Harrison R. A new route to peroxynitrite: A role for xanthine oxidoreductase. FEBS Lett 2000; 475:93-6.

34. Babior BM. The leukocyte NADPH oxidase. Isr Med Assoc J 2002;4:1023-4.

35. Xu P, LaVallee P, Hoidal JR. Repressed expression of the human xanthine oxidoreductase gene. J Biol Chem 2000;275:5918-26.

36. Wu X, Wakamiya M, Vaishnav S, Geske R, Montgomery C Jr., Jones P, et al. Hyperuricemia and urate nephropathy in urate oxidase-deficient mice. Proc Natl Acad Sci U S A 1994;91:742-6.

37. Kadhum HH. Evaluation of Protective Effects of L-carnitine, Atorvastatin, and Vitamin A on Acetaminophen Induced Hepatotoxicity and Nephrotoxicity in Rats [Thesis]. Baghdad: Al-Nahrain University; 2015.

38. Jiang Y, Lin Y, Hu YJ, Song XJ, Pan HH, Zhang HJ, et al. Caffeoylquinic acid derivatives rich extract from Gnaphalium pensylvanicum willd. Ameliorates hyperuricemia and acute gouty arthritis in animal model. BMC Complement Altern Med 2017;17:320.

39. Mo SF, Zhou F, Lv YZ, Hu QH, Zhang DM, Kong LD. Hypouricemic action of selected flavonoids in mice: Structure-activity relationships. Biol Pharm Bull 2007;30:1551-6.

40. Hu QH, Wang C, Li JM, Zhang DM, Kong LD. Allopurinol, rutin, and quercetin attenuate hyperuricemia and renal dysfunction in rats induced by fructose intake: Renal organic ion transporter involvement. Am J Physiol Renal Physiol 2009;297:F1080-91.

41. West J. How Enzyme Activity Changes as Enzyme Concentration Decreases. Sciencing. Available from: https://www.sciencing.com/ enzyme-activity-changes-enzyme-concentration-decreases-10250. html. [Last accessed on 2018 Mar 13].

42. McNally JS, Saxena A, Cai H, Dikalov S, Harrison DG. Regulation of xanthine oxidoreductase protein expression by hydrogen peroxide and calcium. Arterioscler Thromb Vasc Biol 2005;25:1623-8.

43. Azevedo MI, Pereira AF, Nogueira RB, Rolim FE, Brito GA, Wong DV, et al. The antioxidant effects of the flavonoids rutin and quercetin inhibit oxaliplatin-induced chronic painful peripheral neuropathy. Mol Pain 2013;9:53.

44. Acharya CR, Sharma AK, Kanthari ND. Involvement of oxidative stress in patients of gout and antioxidant effect of allopurinol. Int J Med Sci Public Health 2015;4:168-72.

45. Cicerchi C, Li N, Kratzer J, Garcia G, Roncal-Jimenez CA, Tanabe K, et al. Uric acid-dependent inhibition of AMP kinase induces hepatic glucose production in diabetes and starvation: Evolutionary implications of the uricase loss in hominids. FASEB J 2014;28:3339-50.

46. Fujimura Y, Yamauchi Y, Murase T, Nakamura T, Fujita SI, Fujisaka T, et al. Relationship between plasma xanthine oxidoreductase activity and left ventricular ejection fraction and hypertrophy among cardiac patients. PLoS One 2017;12:e0182699.

47. Tsushima Y, Nishizawa H, Tochino Y, Nakatsuji H, Sekimoto R, Nagao $\mathrm{H}$, et al. Uric acid secretion from adipose tissue and its increase in obesity. J Biol Chem 2013;288:27138-49.

48. Sodhi K, Hilgefort J, Banks G, Gilliam C, Stevens S, Ansinelli HA, et al. Uric acid-induced adipocyte dysfunction is attenuated by HO-1 upregulation: Potential role of antioxidant therapy to target obesity. Stem Cells Int 2016;2016:8197325

49. Battelli MG, Polito L, Bolognesi A. Xanthine oxidoreductase in atherosclerosis pathogenesis: Not only oxidative stress. Atherosclerosis 2014;237:562-7.

50. Seo S, Lee MS, Chang E, Shin Y, Oh S, Kim IH, et al. Rutin increases muscle mitochondrial biogenesis with AMPK activation in high-fat diet-induced obese rats. Nutrients 2015;7:8152-69. 